\title{
Analysis of Coal for Safe Producing Low Temperature Carbon Products
}

\author{
Andrey Papin ${ }^{1, *}$, Alexander Nevedrov ${ }^{1}$, Elena Vasileva $^{1}$, and Evgeniya Makarevich ${ }^{1}$ \\ ${ }^{1}$ T.F. Gorbachev Kuzbass State Technical University, 650000, 28 Vesennyaya street, Kemerovo, \\ Russia
}

\begin{abstract}
Solid products of low temperature carbonization in comparison with coke have the higher reaction and adsorption capacity, are easier to undergo the subsequent activation and gasification. The low temperature coke can also act as a refined smokeless fuel for boiler plants and domestic ovens, an active carbonaceous reductant for the chemical and metallurgical industries. The results of Tugnuisky open pit (Buryatia) coal quality studies are given in this article. The parameters of the technical and elemental analysis of the feed coal were tested during the experiments. The low temperature carbonization of coal sample in retort was carried out to determine the yield of the low temperature carbonization products. The produced products were investigated according to the quality indicators in accordance with the requirements of the technical specifications.
\end{abstract}

\section{Introduction}

Low temperature carbonization is a method for processing solid fuels by heating without access to air to $500-650^{\circ} \mathrm{C}$, producing low temperature coke and volatile products, their capturing and processing [1]. The raw base of the process can be a wide range of noncaking stone and brown coals, as well as peat and oil shale. Low temperature carbonization as a process is less common than coking. Meanwhile, solid, liquid and gaseous products of low-temperature pyrolysis of coal have the unique properties that are of great value for the use in industrial processes [2].

The resin, whose yield reaches more than $20 \%$ of the organic mass, contains up to $50 \%$ of phenolic raw materials. The low temperature carbonization gas has a high (more than 20 $\mathrm{MJ} / \mathrm{m}^{3}$ ) calorific value. Consequently, low temperature carbonization is a great opportunity to realize the chemical potential of coal $[3,4]$. The low temperature carbonization became particularly important in recent years, because the modern coal companies are trying to increase the number of products with a higher surplus value compared to ordinary coal.

* Corresponding author: pav.httt@,kuzstu.ru 
To that end, the research on the yield of low temperature carbonization products from the Tugnuisky open pit (Buryatia) coal was carried out.

\section{Materials and Methods}

The indicators of technical analysis of the studied coal and low temperature coke samples were tested as follows: moisture of coal according to State Standard P 52911-2013 "Solid mineral fuel. Test methods for total moisture "[5], State Standard 11014-2001 "Brown coals, stone coals, anthracite and combustible oil shale. Accelerated test methods for moisture" [6], ash content of coal - according to State Standard P 55661-2013 "Solid mineral fuel. Test methods for ash content" [7], volatile yield - according to State Standard P 55660-2013 "Solid mineral fuel. Test methods for the yield of volatile substances" [8]. The content of carbon and hydrogen on dry weight basis was tested in accordance with State Standard 2408.1-95 "Solid fuel. Test methods for carbon and hydrogen "[9-10].

The analysis of the yield of low temperature carbonization products was carried out for the studied coal. The method is based on heating the test coal to $650^{\circ} \mathrm{C}$ in retort, trapping the low temperature carbonization resin and water in the receiver, and following determining their yield by gravimetric method. The primary heating was carried out to 250 ${ }^{\circ} \mathrm{C}$ at the heating rate of $10 \mathrm{deg} / \mathrm{min}$, then the heating rate to $650^{\circ} \mathrm{C}$ was $5 \mathrm{deg} / \mathrm{min}$. The required coal sample size is $0.2 \mathrm{~mm}$.

The scheme of the plant for testing the yield of low temperature carbonization products is shown in Figure 1. The retort 1 is heated by electric furnace 2 . The voltage supplied to the furnace is regulated by laboratory autotransformer. The temperature is controlled by means of thermocouple 3 and a millivoltmeter 4 . The steam-gas mixture from the retort enters the condensate receiver 5 where the resin and water condense. The receiver is cooled in the refrigerator 6 . The pyrolysis gas enters the gas meter 12 due to vacuum in the system; valves 8 and 10 being opened. The vacuum in the system is controlled by manometer 7 .

The analysis of the low temperature carbonization gas taken at temperatures of $500^{\circ} \mathrm{C}$ and $650^{\circ} \mathrm{C}$ was carried out using the chromatograph "Color $800^{\prime \prime}$.

\section{Results and Discussion}

The results of the technical and elemental analysis of low temperature coke, as well as the characteristics of feed coal from which it was produced, are presented in Table 1. 


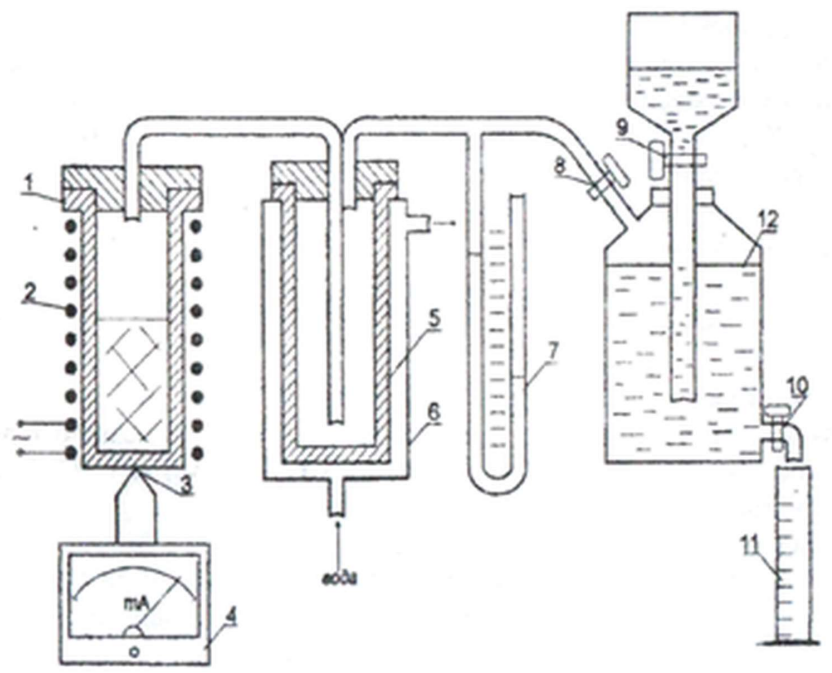

Fig. 1. - The scheme of the plant for testing the yield of low temperature carbonization products: 1 retort; 2 - furnace; 3 - thermocouple; 4 - millivoltmeter; 5 - condensate receiver for resin and water; 6 - cooling-water jacket; 7 - manometer; 8 - three-way valve; 9, 10 - gas meter valves; 11 measuring cylinder; 12 - gas meter

Table 1. Technical analysis of coal and low temperature coke

\begin{tabular}{|c|c|c|c|c|c|c|}
\hline Sample & $\begin{array}{c}\mathrm{W}^{\mathrm{a}}, \% \\
\text { weight }\end{array}$ & $\begin{array}{c}\mathrm{A}^{\mathrm{d}}, \% \\
\text { weight }\end{array}$ & $\begin{array}{c}\mathrm{V}^{\text {daf } \%} \\
\text { weight }\end{array}$ & $\begin{array}{c}\mathrm{C}^{\mathrm{d}} \% \% \\
\text { weight }\end{array}$ & $\begin{array}{c}\mathrm{H}^{\mathrm{d}}, \% \\
\text { weight }\end{array}$ & Coke button \\
\hline Coal & 3.0 & 8.4 & 45.3 & 71.4 & 6.0 & Low-caking \\
\hline Char & 4.5 & 11.9 & 13.6 & 77.8 & 5.4 & Powdery \\
\hline
\end{tabular}

The yield of low temperature coke and chemical low temperature carbonization products products for the studied coal was: low temperature coke $-79 \%$ by weight, free moisture $3.0 \%$ by weight, pyrogenic water and low temperature carbonization resin $-8.4 \%$ by weight, low temperature carbonization coal $-9.6 \%$ by weight.

The results of the analysis of low temperature carbonization gas to test its component composition are presented in Table 2.

Table 2. Component composition of low temperature carbonization gas

\begin{tabular}{|c|c|c|}
\hline Gas Component & Content at $500{ }^{\circ} \mathrm{C}, \%$ volume & Содержание при $650{ }^{\circ} \mathrm{C}, \%$ volume \\
\hline $\mathrm{CO}_{2}$ & 12.5 & 10.5 \\
\hline $\mathrm{CH}_{4}$ & 25.5 & 20.2 \\
\hline $\mathrm{CmHn}$ & 2.6 & 1.5 \\
\hline $\mathrm{CO}$ & 0.9 & 4.9 \\
\hline $\mathrm{H}_{2}+\mathrm{N}_{2}+\mathrm{O}_{2}$ & 58.5 & 62.9 \\
\hline
\end{tabular}


On the basis of experimental data, it can be concluded that in the process of low temperature carbonization due to the pyrolysis of coal matter in low temperature coke, the carbon content increases and the hydrogen content decreases as compared with the feed coal. The entire ash part of the feed coal sample remains in the non-volatile residue. Due to the release of volatile products of low temperature carbonization and, as a consequence, mass loss, the ash content of low temperature coke increases. The ashing coefficient during the transition to low temperature coke for the studied coal is 1.417 .

The yield of low temperature coke is $79 \%$ by weight, of the low temperature carbonization gas is $9.6 \%$ by weight. The maximum emisson of the components of low temperature carbonization gas is observed at the temperature of $500^{\circ} \mathrm{C}$. By the end of low temperature carbonization, when the temperature reaches $600^{\circ} \mathrm{C}$, the content of carbon dioxide, methane and unsaturated hydrocarbons decreases and the content of carbon monoxide and the mixture of hydrogen, nitrogen and oxygen increases. Accordingly, it can be concluded that the most complete course of low temperature carbonization process with the decrease in the yield of the volatile substances of low temperature coke occurs when the coal is heated to $600{ }^{\circ} \mathrm{C}$. At this temperature, the process of resinification ends and the further increase in temperature can lead to its pyrolysis.

\section{Conclusion}

On the basis of the obtained data, it can be concluded that the studied coal can be used in the technological process of low temperature carbonization to produce of low temperature coke and chemical low temperature carbonization products corresponding to the requirements of the technical specifications. According to the indicators of ash content and volatiles release, the produced low temperature coke can belong to the P-2 grade according to the Technical Specifications 0772-003-85230995-2009 and P-2 according to the Technical Specifications 0772-004-85230995-2009.

\section{References}

1. S. A. Akhmetov, M. Kh.Ishmiyarov, A. A. Kaufman, Technology for Processing Oil, Gas and Solid Fossil Fuels (Nedra, St. Petersburg: 2009)

2. Yu. A. Strizhakova, A. N. Ryzhov, I. V. Chuvaeva, E .A. Smolenskiy, A. L. Lapidus, Solid Fuel Chemistry, 13, 6 (2011)

3. M. B. Shkoller, S. N. Dyakov, S. P. Subbotin, Modern Power Technological Processes of Deep Processing of Solid Fuels (KVI, Kemerovo, 2012)

4. M.B. Shkoller. Low Temperature Carbonization of Stone and Brown Coals (NBI, Novokuznetsk, 2001)

5. Solid mineral fuel. Test methods for total moisture (STANDARDINFORM, Moscow, 2014) 
6. Brown coals, stone coals, anthracite and combustible oil shale. Accelerated test methods for moisture (IPC, Moscow, 2002)

7. Solid mineral fuel. Test methods for ash content (IPC, Moscow, 2012)

8. Solid mineral fuel. Test methods for the yield of volatile substances (IPC, Moscow, 2014)

9. Solid fuel. Test methods for carbon and hydrogen (IPC, Moscow, 2010)

10. S.N. D'yakov, A.V. Papin, A.V. Nevedrov, E.V. Zhbyr', Coke and Chemistry, 55:10, 363 (2012) 